\title{
Polychlorinated dibenzo-p-dioxins and polychlorinated dibenzofurans in sewage sludge: congener patterns, toxic equivalency and comparison with effluent concentrations and toxic equivalency
}

\author{
A. Balasubramani \& H. S. Rifai \\ Civil and Environmental Engineering, University of Houston, USA
}

\begin{abstract}
Domestic and industrial wastewater treatment plants, and petrochemical industries within the Houston Ship Channel (HSC) located in Houston, Texas, USA, were sampled for sewage sludge and analysed for polychlorinated dibenzo-p-dioxins and polychlorinated dibenzofurans (PCDD/Fs). The United States Environmental Protection Agency (USEPA) method 1613B which employs high resolution gas chromatography/high resolution mass spectrometry (HRGC/HRMS) was used to quantify the PCDD/Fs in the sludge samples. The measured toxic equivalency (TEQ) across all samples ranged between $0.73 \mathrm{pg} / \mathrm{g}$ and $7348.40 \mathrm{pg} / \mathrm{g}$ dry weight, and the mean TEQ in the industrial sludge was higher than that in the sewage sludge by a factor of 40 . Industrial samples exhibited higher PCDD homolog concentrations and among the PCDF homologs, different congeners exhibited maximum concentrations among the industrial and wastewater sludge samples. It was deduced that both the effluent and sludge from industries exhibited higher furan concentrations, and contributed the most toxicity to receiving waters, due to the high percent contribution of 2,3,7,8-Tetrachlorodibenzodioxin $(2,3,7,8$ TCDD) and 2,3,7,8-Tetrachlorodibenzofuran (2,3,7,8-TCDF) towards total TEQ. Comparing sludge samples with the effluent samples led to the observation that the total TEQ in sludge samples was significantly higher than that in effluent samples obtained from the same facility, thereby indicating the difference in source of PCDD/Fs between industries and sewerage systems.
\end{abstract}

Keywords: PCDD/Fs, homologs, Houston Ship Channel, persistent organic pollutants, wastewater, effluent. 


\section{Introduction}

Polychlorinated dibenzo-p-dioxins and polychlorinated dibenzofurans (PCDD/Fs) are released into the environment by various sources, such as atmospheric deposition, discharge from industries, and domestic water, among others [1-3]. $\mathrm{PCDD} / \mathrm{Fs}$ accumulate in the environment, making them both a human health concern and environmental concern. Previous studies have investigated sewage sludge for the presence of PCDD/Fs in order to understand the sources, fate of these contaminants, and to understand the safety of applying sludge on agricultural lands as a means of disposal $[4,5]$.

Characterization of PCDD/Fs from sludge samples obtained from municipal treatment plants has been described in the literature, with the earliest being done in Henriksdal, Stockholm and Balinge, Sweden by Rappe et al. [2], in which they observed lower homologs to be below $15 \mathrm{ppt}$ and that the homolog patterns of the sludge samples were similar to those observed in sediment and air samples. Sewart et al. [6] analyzed sewage sludge collected from 12 sewage treatment plants in England and observed that the high toxic equivalency (TEQ) was due to elevated concentrations of hexa through octa homologs and that their harmful effects need to be further reviewed before applying onto agricultural land.

Recently, various studies have examined the presence and distribution of $\mathrm{PCDD} / \mathrm{Fs}$ and dioxin-like polychlorinated biphenyls (PCBs) in sludge samples. Eight sludge samples obtained from rural, urban, and industrial wastewater treatment plants in Spain was analyzed by Eljarrat et al. [7] and it was determined that octochlorodibenzodioxin (OCDD) and octachlorodibenzofuran (OCDF) were the dominant species across all the samples. This observation of OCDD and OCDF being the dominant species in sludge samples collected from wastewater treatment plants was also observed in subsequent studies [8,9].

In this study, sludge samples obtained from 43 wastewater facilities in Houston, Texas, USA, that discharge into the Houston Ship Channel (HSC) were analysed, with the goal of describing the environmental impact the dioxin loads being released from these facilities have on the HSC. The HSC was sampled for sewage sludge with the goal of determining the concentrations and distribution of the 17 most toxic PCDD/F congeners and homologs, comparing and contrasting the congener signatures between sludge obtained from different types of facilities, and evaluating the similarities between the PCDD/Fs in effluent and sludge samples.

\section{Materials and methods}

\subsection{Sample collection}

The HSC in Houston, Texas, is associated with pulp and paper mills, shipping, and petrochemical refineries, along with other industrial activities that have been identified as potential sources of PCDD/Fs, and has been studied widely [10-17]. Figure 1 shows the locations of the 43 facilities in this study that were sampled for sludge in 2002. Out of the 43 facilities, twenty seven were industries (I1 through I27), fourteen were domestic sewerage systems (WWTP1 through WWTP14), and 
two were industrial sewerage systems (O1, and O2). Two industries (I11, and I14), and two of the domestic sewerage systems (WWTP3, and WWTP10) were sampled in duplicate.

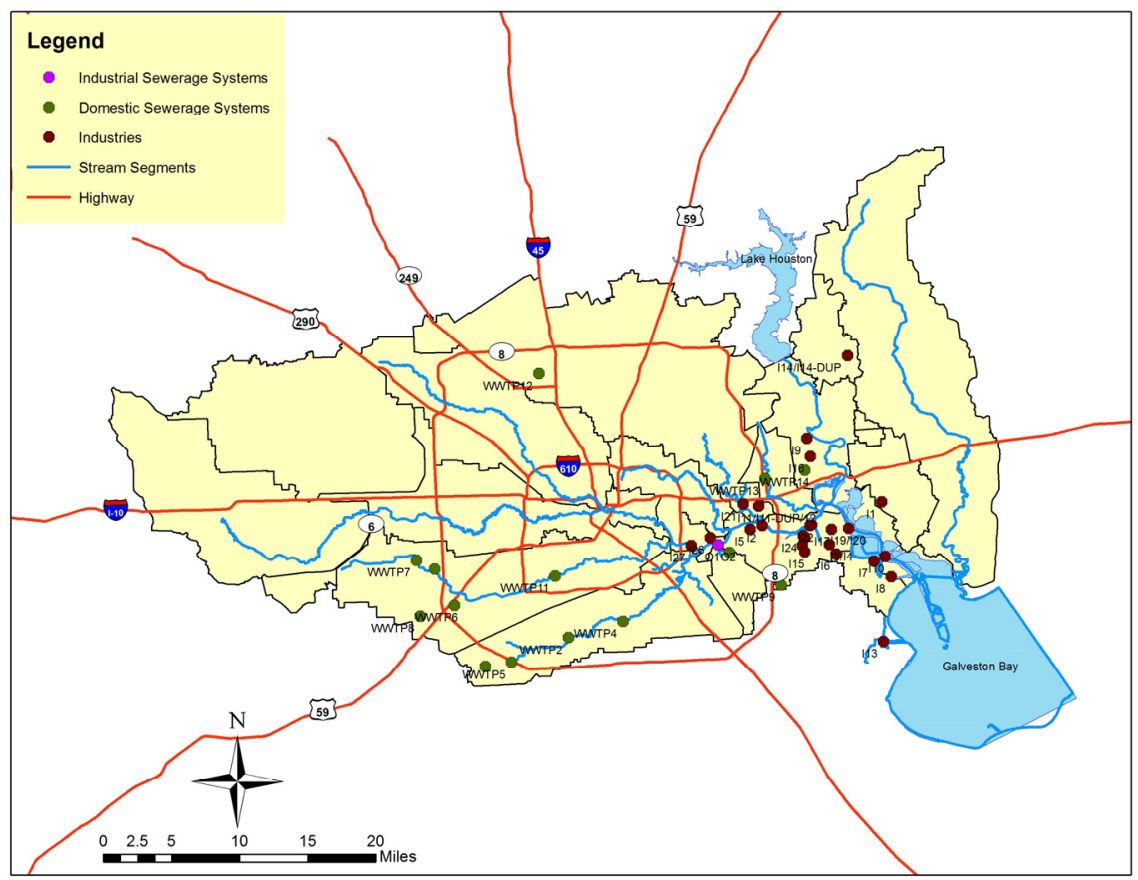

Figure 1: Location of the facilities where sludge samples were collected.

Sludge samples were collected from three sources within the facilities: recirculation lines, belt presses, and settling ponds, each sampled using a different technique. Samples were collected from recirculation lines by placing a sample container under the outlet valve and opening it to allow the sludge to flow into the container. Dried sludge was taken off the belt and placed in stainless steel containers, while the sample from ponds was collected using a Teflon-lined scoop or dredge, depending on the depth of the pond. In addition to the dioxin sample, separate grab samples were collected at each facility and analysed for total organic carbon (TOC).

\subsection{Chemical analyses}

The 17 most toxic PCDD/Fs [18] were quantified using high resolution gas chromatography/high mass spectrometry (HRGC/HRMS) using USEPA method $1613 \mathrm{~B}$ by a commercial laboratory that met the data quality objective established for this study. Sludge samples were homogenized, dried, spiked with fifteen ${ }^{13} \mathrm{C}_{12}$ labeled $\mathrm{PCDD} / \mathrm{F}$ internal standards, and extracted for 18-24 hours using 
methylene chloride, and hexane in a Soxhlet extraction apparatus, followed by spiking with $2,3,7,8-\mathrm{TCDD}{ }^{37} \mathrm{C}_{14}$ enrichment efficiency standard before subjecting the extracts to acid/base washes, and carbon clean-up procedures to remove interferences from the extracts. Finally, the extracts were concentrated to near dryness and spiked with recovery standards and chromatographic separation was achieved with a DB-5 capillary chromatograph column for PCDD/Fs. Also, TOC was analysed by SM 5310C.

\section{Results and discussion}

\subsection{Detection and distribution of PCDD/F congeners}

Table 1 provides the percent TOC in each sample, the number of detects obtained in the various sludge samples (i.e. how many of the 17 congeners are present above their respective detection limit in the sample), \% detection, and the World Health Organization (WHO) TEQPCDD/Fs contributions in the sludge samples. A total of 36 out of the 47 samples exhibited greater than 50\% detection, with OCDD being detected in all the samples, followed by OCDF and 1,2,3,4,6,7,8Heptachlorodibenzodioxin $(1,2,3,4,6,7,8-\mathrm{HpCDD})$ being detected in 42 and 44 sludge samples respectively. As can be seen in Table 1, the sewerage system had a more regular rate of detection than the industries. This could be due to the fact that sewerage systems receive a mixture of different types of urban dioxin sources because of their large service areas.

It was expected that the congeners that exhibited maximum congener concentrations would not exhibit the maximum TEQ. As stated above, OCDD and OCDF exhibited the highest congener concentrations in the 47 samples, while the tetra, penta, hexa, and hepta congeners exhibited the highest TEQ. It can be seen from Figure 2 that a consistent pattern of OCDD exhibiting the highest concentration in wastewater sludge, followed by OCDF and 1,2,3,4,6,7,8$\mathrm{HpCDD}$, was similar to what has been observed in previous studies [7-9, 19].

In contrast, different congeners exhibited maximum concentrations in different industrial sludge samples (see Figure 2), which could be due to the difference between the industries; this was also consistent with previous studies [20, 21]. It is also noteworthy that the percent contribution of 2,3,7,8-TCDD and 2,3,7,8TCDF towards the overall TEQ was higher in the industrial sludge samples than the wastewater sludge samples. Median percent contribution of 2,3,7,8-TCDD towards the overall TEQ in industrial sludge samples was $7.81 \%$ whereas it was $6.14 \%$ in the wastewater sludge samples, and 2,3,7,8-TCDF exhibited median values of $2.9 \%$ and $1.88 \%$ for the sludge samples obtained from industries and wastewater treatment plants, respectively. This confirms that though the wastewater treatment plants contribute more dioxin load to receiving waters, the industries would contribute most of the toxicity due to the higher presence of $2,3,7,8-\mathrm{TCDD}$ and $2,3,7,8-\mathrm{TCDF}$ in them; the two congeners that are inherently more toxic than the other PCDD/F congeners [18]. 
Table 1: Number of detects, \% detection, TOC, and TEQ of PCDD/Fs in the sludge samples.

\begin{tabular}{|c|c|c|c|c|}
\hline Facility & \# Detects & $\%$ Detection & WHO TEQPCDD/Fs $(\mathrm{pg} / \mathrm{g})$ & TOC (\%) \\
\hline I1 & 15 & $88 \%$ & 186.36 & 9.3 \\
\hline I2 & 12 & $71 \%$ & 3.17 & 3.79 \\
\hline I3 & 15 & $88 \%$ & 12.58 & 32.5 \\
\hline I4 & 8 & $47 \%$ & 1.03 & 13.7 \\
\hline I5 & 11 & $65 \%$ & 2.8 & 0.6 \\
\hline I6 & 6 & $35 \%$ & 9.66 & 5.01 \\
\hline I7 & 12 & $71 \%$ & 2.83 & 5.29 \\
\hline I8 & 16 & $94 \%$ & 6.52 & 8.64 \\
\hline I9 & 11 & $65 \%$ & 28.01 & 22 \\
\hline I10 & 9 & $53 \%$ & 2.34 & 0.13 \\
\hline I11 & 17 & $100 \%$ & 2278.3 & 24.7 \\
\hline I11-DUP & 17 & $100 \%$ & 7348.4 & 20.3 \\
\hline I12 & 12 & $71 \%$ & 898.94 & 16.4 \\
\hline I13 & 11 & $65 \%$ & 2.78 & 24.4 \\
\hline I14 & 9 & $53 \%$ & 27.17 & 22.2 \\
\hline I14-DUP & 13 & $76 \%$ & 32.52 & 22.1 \\
\hline I15 & 2 & $12 \%$ & 0.73 & 7.01 \\
\hline I16 & 2 & $12 \%$ & 4.03 & 30.6 \\
\hline I17 & 16 & $94 \%$ & 26.13 & 0.34 \\
\hline I18 & 12 & $71 \%$ & 48.79 & 1.36 \\
\hline I19 & 13 & $76 \%$ & 258.48 & 5.45 \\
\hline I2O & 14 & $82 \%$ & 11.64 & 3.01 \\
\hline I21 & 1 & $6 \%$ & 5.67 & 0.28 \\
\hline I22 & 3 & $18 \%$ & 54.44 & 6.43 \\
\hline I23 & 1 & $6 \%$ & 6.95 & 7.58 \\
\hline I24 & 17 & $100 \%$ & 469.38 & 28.9 \\
\hline I25 & 15 & $88 \%$ & 28.29 & 16.7 \\
\hline I26 & 11 & $65 \%$ & 5.01 & 16.2 \\
\hline I27 & 14 & $82 \%$ & 14.2 & 31.4 \\
\hline WWTP 1 & 14 & $82 \%$ & 27.81 & 19.6 \\
\hline WWTP2 & 8 & $47 \%$ & 2.13 & 19.3 \\
\hline WWTP3 & 8 & $47 \%$ & 6.77 & 20.5 \\
\hline WWTP3-DUP & 11 & $65 \%$ & 6.41 & 19.3 \\
\hline WWTP4 & 13 & $76 \%$ & 16.77 & 15 \\
\hline WWTP5 & 12 & $71 \%$ & 10.72 & 19.3 \\
\hline WWTP6 & 10 & $59 \%$ & 2.65 & 24.3 \\
\hline WWTP7 & 12 & $71 \%$ & 10.76 & 17.4 \\
\hline WWTP8 & 12 & $71 \%$ & 8.67 & 16.8 \\
\hline WWTP9 & 13 & $76 \%$ & 10.87 & 16.5 \\
\hline WWTP 10 & 13 & $76 \%$ & 24.29 & 22.2 \\
\hline WWTP10-DUP & 11 & $65 \%$ & 13.68 & 17.2 \\
\hline WWTP11 & 12 & $71 \%$ & 5.97 & 15.3 \\
\hline WWTP 12 & 11 & $65 \%$ & 7.19 & 20 \\
\hline WWTP 13 & 9 & $53 \%$ & 13.25 & 22.4 \\
\hline WWTP 14 & 11 & $65 \%$ & 5.56 & 16.8 \\
\hline $\mathrm{O} 1$ & 6 & $35 \%$ & 7.15 & 22.4 \\
\hline $\mathrm{O} 2$ & 6 & $35 \%$ & 4.78 & 27 \\
\hline
\end{tabular}




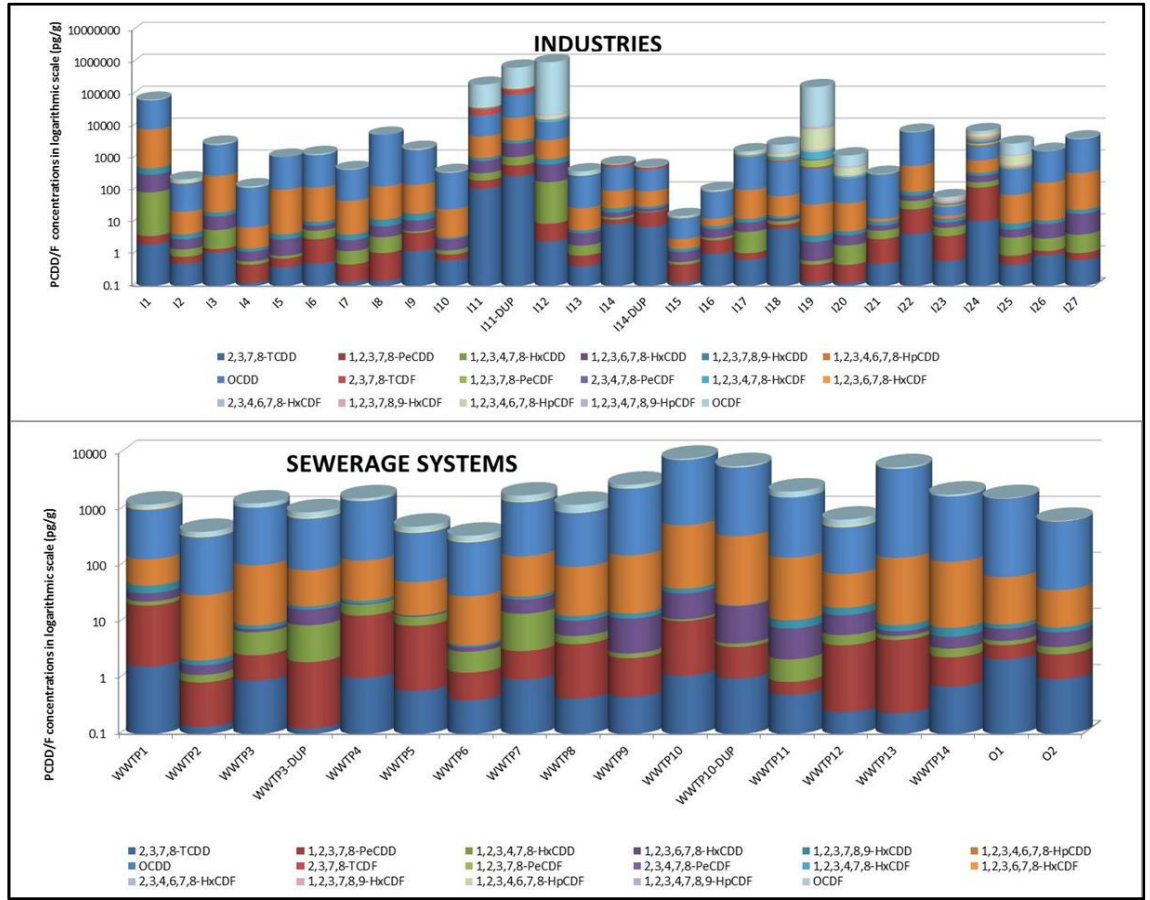

Figure 2: Distribution of $\mathrm{PCDD} / \mathrm{F}$ congener concentrations in sampled domestic and industrial sewerage systems. (Non-detects $=1 / 2$ method detection limit (MDL)).

\subsection{Total PCDD/F TEQ contributions in the sludge samples}

The measured congener concentrations were multiplied by the corresponding WHO TEF values [18] and summed to obtain the total PCDD/F TEQ (see Table 1). In the industrial samples the TEQ ranged from $0.73 \mathrm{pg} / \mathrm{g}$ to $7348.40 \mathrm{pg} / \mathrm{g}$ dry weight with a median value of $12.6 \mathrm{pg} / \mathrm{g}$ dry weight. The TEQ ranged from 2.13 $\mathrm{pg} / \mathrm{g}$ to $27.8 \mathrm{pg} / \mathrm{g}$ dry weight with a median value of $9.69 \mathrm{pg} / \mathrm{g}$ dry weight at the sewerage facilities.

It was recognized that $1,2,3,7,8$-Pentachlorodibenzodioxin $(1,2,3,7,8-\mathrm{PeCDD})$ was the major contributor towards TEQ in most of the sewerage systems, whereas no specific pattern was observed in the industrial sludge samples, which could be once again due to the diversity of the products handled by these industries.

Interestingly, the mean TEQ of PCDD/Fs in industrial sludge $(406.1 \mathrm{ng} / \mathrm{kg})$ was approximately 40 times higher than that in the sewage sludge $(10.3 \mathrm{ng} / \mathrm{kg})$, which was in contrast to the industrial sludge being 20 times higher than sewage sludge seen in Hwang et al. [20]. This finding further affirms that the sludge obtained from industries in and around the HSC is diverse in terms of its constituents and contains relatively significant amounts of PCDD/Fs. 


\section{3 $\mathrm{PCDD} / \mathrm{F}$ homolog concentrations and patterns}

The PCDD/F homolog concentrations were calculated by summing the concentrations of the congeners with the same number of chlorine atoms. At the industrial facilities, the PCDD homolog concentration in the sludge samples ranged between $0.13 \mathrm{pg} / \mathrm{g}$ and $15 \mathrm{ng} / \mathrm{g}$ dry weight (OCDD excluded), with total HpCDD exhibiting the highest concentration in some of the samples. On the other hand, at the 18 wastewater treatment plants shown in Figure 3, the PCDD homolog concentration in the sludge samples was ten times lower and ranged from 0.13 $\mathrm{pg} / \mathrm{g}$ to $490 \mathrm{pg} / \mathrm{g}$ dry weight (OCDD excluded), with a more consistent pattern of total HpCDD exhibiting the highest concentrations across all the 18 samples.

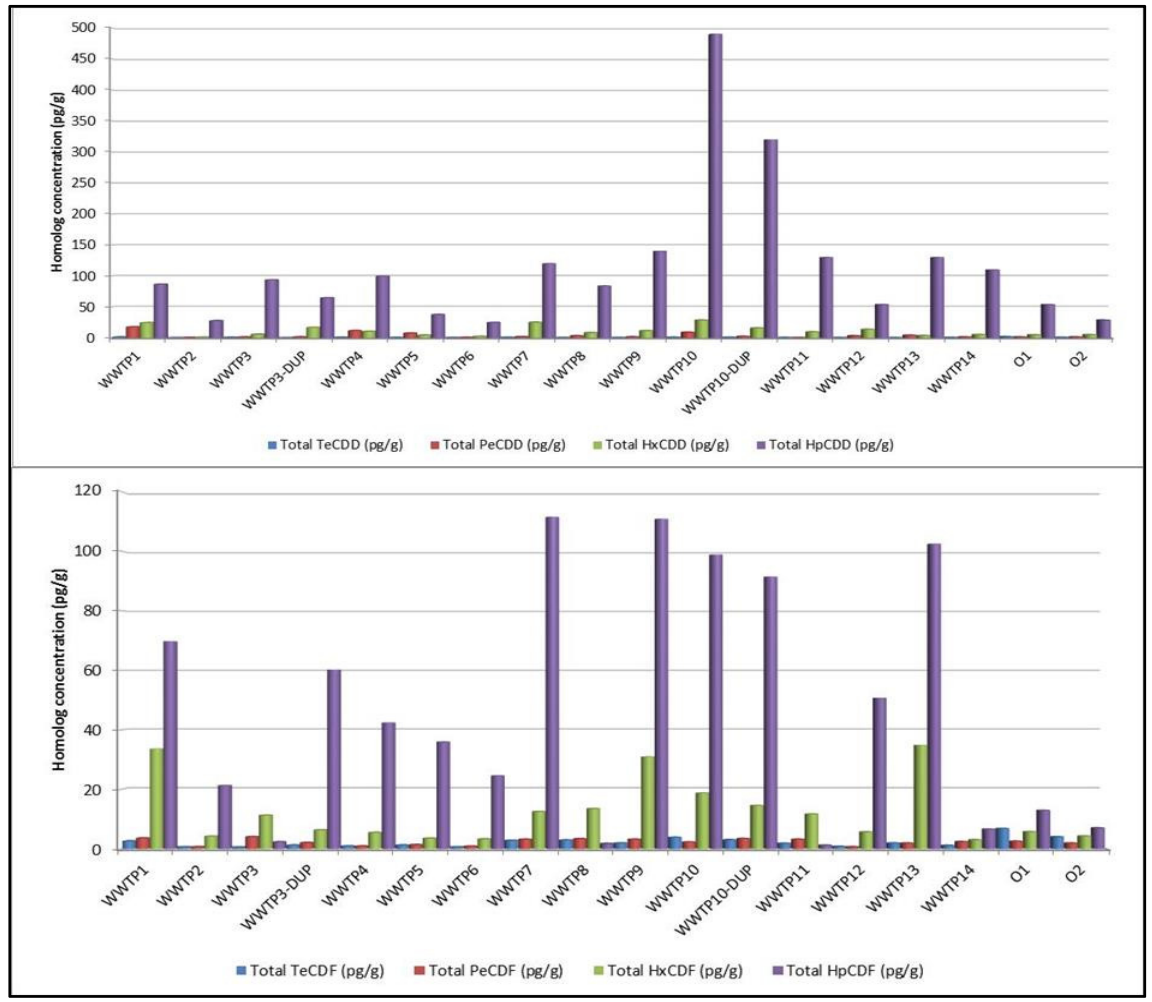

Figure 3: $\mathrm{PCDD} / \mathrm{F}$ homolog concentration in sampled wastewater treatment plants (OCDD and OCDF excluded to facilitate better viewing of other homologs). (Non-detects $=1 / 2 \mathrm{MDL})$.

The PCDF homolog concentration in the industrial sludge samples ranged between $0.085 \mathrm{pg} / \mathrm{g}$ and $14.30 \mathrm{ng} / \mathrm{g}$ dry weight (OCDF excluded), with total tetrachlorodibenzofuran (TeCDF) exhibiting the maximum concentration in some of the samples. In comparison, the PCDF homolog concentrations in wastewater sludge samples ranged between $0.43 \mathrm{pg} / \mathrm{g}$ and $111.50 \mathrm{pg} / \mathrm{g}$ dry weight (OCDF 
excluded), with total heptachlorodibenzofuran (HpCDF) dominating in all the samples (Figure 3).

The ratio of TEQPCDD/TEQPCDF ranged from 0.005 to 11.93 , and was generally greater than 1 for the 16 wastewater treatment plants (domestic + industrial), in agreement with a previous study [22]. Nonetheless, 12 out of the 27 industrial sludge samples contained more furans than dioxins. Ratios of PCDD to pentachlorodibenzofuran (PCDF), OCDD to OCDF, and HpCDD to HpCDF were calculated and compared with previously published data [23-25], leading to the conclusion that the $\mathrm{PCDD} / \mathrm{F}$ contamination in a few of the samples could be attributed to organochlorine, pentachlorophenol, and chloroaniline.

\subsection{Comparison of PCDD/F concentrations in sludge and effluent samples}

Effluent samples were collected from some of the same facilities in this study in spring 2003 and is described in detail in Sappington et al. [26]. The effluent data were compared to the sludge data from the same facilities to evaluate any possible similarities among the two matrices. Even though the sludge and effluent samples were collected at different times, the comparison is still useful as there were no significant changes in the operation or products being manufactured at the studied facilities.

A total of 18 industrial locations, 11 domestic sewerage systems, and 2 industrial sewerage systems, were co-sampled and their data is used here. The total TEQ of the sludge and the suspended mass TEQ in effluent $\left(\mathrm{C}_{\text {susp }}\left[\mathrm{TSS}^{-1}\right)\right.$ results were compared and it was observed that the sludge had a significantly higher total TEQ than the corresponding effluent (see Figure 4). Only seven out of the 31 outfalls exhibited higher total TEQ in the effluent, which included six industrial effluents and a domestic sewerage system. This could be attributed to the possibility that the industrial treatment processes were not as effective as wastewater treatment plants in removing dioxins in their sludge, or due to the higher organic carbon content (median $\mathrm{TOC}=80.40 \mathrm{mg} / \mathrm{L}$, median dissolved organic carbon $=47.05 \mathrm{mg} / \mathrm{L}$ ) in industrial effluents.

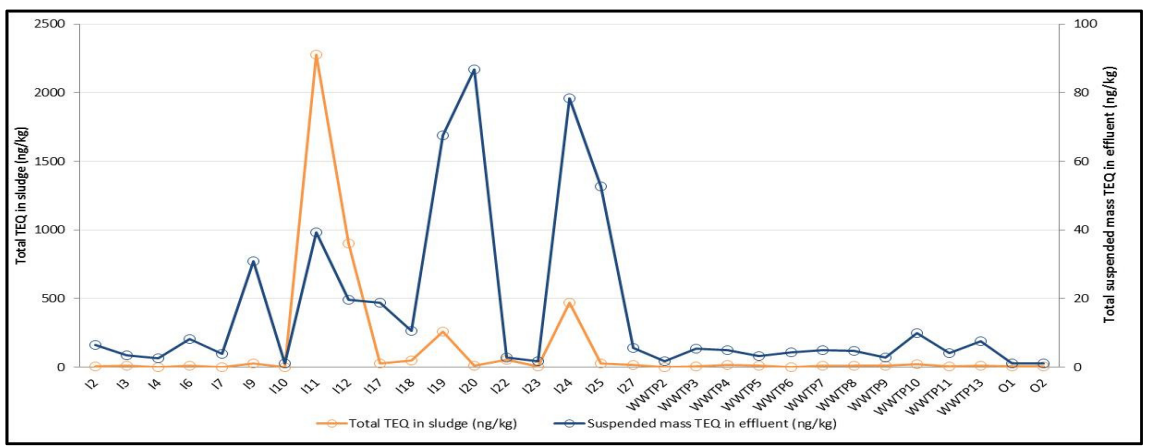

Figure 4: Total TEQ sludge in sludge vs total suspended mass TEQ in effluent at the sampled sites. 
It was observed that in the effluent and sludge samples obtained from the industries, 12 out of the 18 samples exhibited dioxins as their lowest concentrations, thereby being consistent with the known fact that the presence of furans is indicative of the presence of an industrial source. As this trend was not observed in the sewerage systems, it can be concluded that the sources of PCDD/F in sludge obtained from industries and sewerage systems are very different. This could be due to air deposition being a source for sewerage systems, as noted by other studies [8, 27], whereas in the case of industrial effluents, the dioxin signature is more dependent on the type of products being manufactured.

\section{Conclusions}

This is the first study to quantify the 17 most toxic PCDD/F congeners in sludge samples obtained from different domestic and industrial wastewater treatment plants and petrochemical industries that discharge into the HSC in Houston, Texas, USA. Overall, it was observed that the sewerage systems had a more frequent rate of detection of PCDD/Fs than industries, with OCDD and OCDF being detected in almost all of the samples.

Industrial effluent and sludge, on the other hand exhibited higher furan concentrations as might be expected, and sewerage systems had higher dioxins. It was also concluded that industries would contribute the most toxicity to receiving waters, as the percent contribution of 2,3,7,8-TCDD and 2,3,7,8-TCDF towards the overall TEQ was higher in industrial sludge. In addition, the mean TEQ of $\mathrm{PCDD} / \mathrm{Fs}$ in industrial sludge was 40 times higher than that observed in the sewerage systems, demonstrating that the specificity of dioxin signatures in sludge depended on the type of industry.

Lastly, the total TEQ in sludge, when compared to the effluent obtained from the same facilities was much higher confirming that the sources of PCDD/Fs in sewerage systems and industries are very different. While air deposition could be a possible source of $\mathrm{PCDD} / \mathrm{F}$ contamination in the sewerage systems, the contamination in industrial effluents is a result of the type of products being manufactured at that facility.

\section{References}

[1] Lohmann, R. and Jones, K.C., Dioxins and furans in air and deposition: A review of levels, behaviour and processes. Science of The Total Environment, 1998. 219(1): pp. 53-81.

[2] Rappe, C., Kjeller, L.-O., and Andersson, R., Analyses of PCDDs and PCDFs in sludge and water samples. Chemosphere, 1989. 19(1-6): pp. 1320.

[3] Vizard, C.G., Rimmer, D.L., Pless-Mulloli, T., Singleton, I., and Air, V.S., Identifying contemporary and historic sources of soil polychlorinated dibenzo-p-dioxins and polychlorinated dibenzofurans in an industrial urban setting. Science of the Total Environment, 2006. 370(1): pp. 61-69. 
[4] Harrison, E.Z., Oakes, S.R., Hysell, M., and Hay, A., Organic chemicals in sewage sludges. Science of the Total Environment, 2006. 367(2-3): pp. 481497.

[5] Rogers, H.R., Sources, behaviour and fate of organic contaminants during sewage treatment and in sewage sludges. Science of The Total Environment, 1996. 185(1-3): pp. 3-26.

[6] Sewart, A., Harrad, S.J., McLachlan, M.S., McGrath, S.P., and Jones, K.C., $P C D D / F s$ and non-o-PCBs in digested U.K. sewage sludges. Chemosphere, 1995. 30(1): pp. 51-67.

[7] Eljarrat, E., Caixach, J., and Rivera, J., A comparison of TEQ contributions from PCDDs, PCDFs and dioxin-like PCBs in sewage sludges from Catalonia, Spain. Chemosphere, 2003. 51(7): pp. 595-601.

[8] Dai, J., Xu, M., Chen, J., Yang, X., and Ke, Z., PCDD/F, PAH and heavy metals in the sewage sludge from six wastewater treatment plants in Beijing, China. Chemosphere, 2007. 66(2): pp. 353-361.

[9] Fuentes, M.J., Font, R., Gómez-Rico, M.F., and Moltó, J., Multivariant statistical analysis of PCDD/FS in sewage sludges from different areas of the Valencian Community (Spain). Chemosphere, 2007. 67(7): pp. 14231433.

[10] Correa, O., Raun, L., Rifai, H., Suarez, M., Holsen, T., and Koenig, L., Depositional flux of polychlorinated dibenzo-p-dioxins and polychlorinated dibenzofurans in an urban setting. Chemosphere, 2006. 64(9): pp. 15501561.

[11] Correa, O., Rifai, H., Raun, L., Suarez, M., and Koenig, L., Concentrations and vapor-particle partitioning of polychlorinated dibenzo-p-dioxins and dibenzofurans in ambient air of Houston, TX. Atmospheric Environment, 2004. 38(39): pp. 6687-6699.

[12] Dean, K.E., Suarez, M.P., Rifai, H.S., Palachek, R.M., and Larry, K., Bioaccumulation of polychlorinated dibenzodioxins and dibenzofurans in catfish and crabs along an estuarine salinity and contamination gradient. Environmental Toxicology and Chemistry, 2009. 28(11): pp. 2307-2317.

[13] Raun, L.H., Correa, O., Rifai, H., Suarez, M., and Koenig, L., Statistical investigation of polychlorinated dibenzo-p-dioxins and dibenzofurans in the ambient air of Houston, Texas. Chemosphere, 2005. 60(7): pp. 973-989.

[14] Suarez, M.P., Rifai, H.S., Palachek, R., Dean, K., and Koenig, L., Distribution of polychlorinated dibenzo-p-dioxins and dibenzofurans in suspended sediments, dissolved phase and bottom sediment in the Houston Ship Channel. Chemosphere, 2006a. 62(3): pp. 417-429.

[15] Suarez, M.P., Rifai, H.S., Palachek, R.M., Dean, K.E., and Koenig, L., Polychlorinated dibenzo-p-dioxins and dibenzofurans in Houston Ship Channel tissue and sediment. Environmental Engineering Science, 2005. 22(6): pp. 891-906.

[16] Suarez, M.P., Rifai, H.S., Schimek, J., Bloom, M., Jensen, P., and Koenig, L., Dioxin in storm-water runoff in Houston, Texas. Journal of Environmental Engineering, 2006b. 132(12): pp. 1633-1643. 
[17] Yeager, K.M., Santschi, P.H., Rifai, H.S., Suarez, M.P., Brinkmeyer, R., Hung, C.C., Schindler, K.J., Andres, M.J., and Weaver, E.A., Dioxin chronology and fluxes in sediments of the Houston ship channel, Texas: Influences of non-steady-state sediment transport and total organic carbon. Environmental Science and Technology, 2007. 41(15): pp. 5291-5298.

[18] Van den Berg, M., Birnbaum, L.S., Denison, M., De Vito, M., Farland, W., Feeley, M., Fiedler, H., Hakansson, H., Hanberg, A., Haws, L., Rose, M., Safe, S., Schrenk, D., Tohyama, C., Tritscher, A., Tuomisto, J., Tysklind, M., Walker, N., and Peterson, R.E., The 2005 World Health Organization reevaluation of human and mammalian toxic equivalency factors for dioxins and dioxin-like compounds. Toxicological Sciences, 2006. 93(2): pp. 223241.

[19] Martínez, K., Abad, E., Palacios, O., Caixach, J., and Rivera, J., Assessment of polychlorinated dibenzo-p-dioxins and dibenzofurans in sludges according to the European environmental policy. Environment International, 2007. 33(8): pp. 1040-1047.

[20] Hwang, I.K., Kang, H.H., Lee, I.S., and Oh, J.E., Assessment of characteristic distribution of PCDD/Fs and BFRs in sludge generated at municipal and industrial wastewater treatment plants. Chemosphere, 2012. 88(7): pp. 888-894.

[21] Ju, J.H., Lee, I.S., Sim, W.J., Eun, H., and Oh, J.E., Analysis and evaluation of chlorinated persistent organic compounds and PAHs in sludge in Korea. Chemosphere, 2009. 74(3): pp. 441-447.

[22] de Souza Pereira, M. and Kuch, B., Heavy metals, PCDD/F and PCB in sewage sludge samples from two wastewater treatment facilities in Rio de Janeiro State, Brazil. Chemosphere, 2005. 60(7): pp. 844-853.

[23] Horstmann, M. and McLachlan, M.S., Textiles as a source of polychlorinated dibenzo-p-dioxins and dibenzofurans $(P C D D / F)$ in human skin and sewage sludge. Environmental Science and Pollution Research, 1994. 1(1): pp. 15-20.

[24] Hutzinger, O. and Fiedler, H., From source to exposure: Some open questions. Chemosphere, 1993. 27(1-3): pp. 121-129.

[25] Nie, Z., Tang, Z., Zhu, X., Yang, Y., Fu, H., Die, Q., Wang, Q., and Huang, Q., Occurrence, possible sources, and temporal trends of polychlorinated dibenzo-p-dioxins and dibenzofurans in water and sediment from the lower Yangtze River basin, Jiangsu and Shanghai areas of Eastern China. Environmental Science and Pollution Research, 2013. 20(12): pp. 87518762.

[26] Sappington, E.N., Balasubramani, A., and Rifai, H.S., Polychlorinated dibenzo-p-dioxins and polychlorinsted dibenzofurans (PCDD/Fs) in municipal and industrial effluents. Chemosphere, 2015. (in publication).

[27] De la Torre, A., Alonso, E., Concejero, M.A., Sanz, P., and Martínez, M.A., Sources and behaviour of polybrominated diphenyl ethers (PBDEs), polychlorinated dibenzo-p-dioxins and dibenzofurans (PCDD/Fs) in Spanish sewage sludge. Waste Management, 2011. 31(6): pp. 1277-1284. 